\title{
The formation of urea in space
}

\section{Ion-molecule, neutral-neutral, and radical gas-phase reactions}

\author{
Flavio Siro Brigiano $^{1}$, Yannick Jeanvoine ${ }^{1}$, Antonio Largo ${ }^{2}$, and Riccardo Spezia ${ }^{1, \star}$ \\ 1 LAMBE, Univ. Evry, CNRS, CEA, Université Paris-Saclay, 91025 Evry, France \\ e-mail: riccardo.spezia@univ-evry.fr \\ ${ }^{2}$ Computational Chemistry Group, Departamento de Quimica Fisica, Facultad de Ciencias, Universidad de Valladolid, \\ 47002 Valladolid, Spain
}

Received 21 July 2017 / Accepted 1 November 2017

\begin{abstract}
Context. Many organic molecules have been observed in the interstellar medium thanks to advances in radioastronomy, and very recently the presence of urea was also suggested. While those molecules were observed, it is not clear what the mechanisms responsible to their formation are. In fact, if gas-phase reactions are responsible, they should occur through barrierless mechanisms (or with very low barriers). In the past, mechanisms for the formation of different organic molecules were studied, providing only in a few cases energetic conditions favorable to a synthesis at very low temperature. A particularly intriguing class of such molecules are those containing one $\mathrm{N}-\mathrm{C}-\mathrm{O}$ peptide bond, which could be a building block for the formation of biological molecules. Urea is a particular case because two nitrogen atoms are linked to the $\mathrm{C}-\mathrm{O}$ moiety. Thus, motivated also by the recent tentative observation of urea, we have considered the synthetic pathways responsible to its formation.

Aims. We have studied the possibility of forming urea in the gas phase via different kinds of bi-molecular reactions: ion-molecule, neutral, and radical. In particular we have focused on the activation energy of these reactions in order to find possible reactants that could be responsible for to barrierless (or very low energy) pathways.

Methods. We have used very accurate, highly correlated quantum chemistry calculations to locate and characterize the reaction pathways in terms of minima and transition states connecting reactants to products.

Results. Most of the reactions considered have an activation energy that is too high; but the ion-molecule reaction between $\mathrm{NH}_{2} \mathrm{OH}_{2}^{+}$ and formamide is not too high. These reactants could be responsible not only for the formation of urea but also of isocyanic acid, which is an organic molecule also observed in the interstellar medium.
\end{abstract}

Key words. astrochemistry - astrobiology - methods: numerical - ISM: molecules - ISM: kinematics and dynamics

\section{Introduction}

In recent years a growing number of organic molecules have been detected in space, in particular in the interstellar medium (ISM) thanks to advances in radioastronomy, and in comets (e.g. the recent mission on the P67/Churyumov-Gerasimenko comet) already reported the presence of some interesting molecules like methyl isocyanate, acetone, acetamide, propionaldehyde, and glycine (Goesmann et al. 2015; Altwegg et al. 2016) and more are expected in the near future). A particularly interesting class of organic molecules is that containing $\mathrm{N}-\mathrm{C}$ single bonds, since these molecules can be the precursors for direct formation of peptides without passing from the single amino acids, as was initially suggested by Rubin et al. (1971) together with formamide $\left(\mathrm{H}_{2} \mathrm{NCHO}\right)$ observation in the ISM. After formamide, other molecules containing $\mathrm{N}-\mathrm{C}$ bonds were found in the ISM, like cyanamide $\left(\mathrm{H}_{2} \mathrm{NCN}\right.$, Turner et al. 1975), $\mathrm{H}_{3} \mathrm{CNC}$ (Cernicharo et al. 1988; Gratier et al. 2013), acetamide $\left(\mathrm{H}_{2} \mathrm{NCOCH}_{3}\right.$, Hollis et al. 2006), cyanoformaldehyde (CNCHO, Remijan et al. 2008), $\mathrm{H}_{2} \mathrm{NCO}^{+}$(Gupta et al. 2013), methylamine $\left(\mathrm{H}_{3} \mathrm{CNH}_{2}\right.$, Kaifu et al. 1974; Fourikis et al. 1974),

\footnotetext{
* Present address: Sorbonne Universités, UPMC Univ. Paris 06, UMR - CNRS 7616, Laboratoire de Chimie Théorique, 75252 Paris, France.
}

aminoacetonitrile $\left(\mathrm{H}_{2} \mathrm{NCH}_{2} \mathrm{CN}\right.$, Belloche et al. 2008), and, very recently, urea $\left(\left(\mathrm{H}_{2} \mathrm{~N}\right)_{2} \mathrm{CO}\right.$, Remijan et al. 2014) and $\mathrm{N}$-methylformamide $\left(\mathrm{H}_{3} \mathrm{CNHCHO}\right.$, Belloche et al. 2017). Urea has the peculiarity of containing two $\mathrm{N}-\mathrm{C}$ bonds and it is considered to be very important for the formation of life, since it can be a precursor for the synthesis of cytosine and uracil (Kolb 2014). A tentative detection of urea in Sgr B2 molecular cloud was reported by collecting data from four independent astronomical instrumentations (Remijan et al. 2014). Extraterrestrial urea was observed previously in the Murchinson C2 chondrite (Hayats et al. 1975) and its presence was suggested on grain mantles (Raunier et al. 2004).

From the point of view of astrochemistry, the question that arises, related to the observation of these organic molecules, concerns the mechanisms that can be responsible for their synthesis. In general, low temperature environments promote only barrierless reaction pathways. Following this hypothesis, quantum chemistry calculations reported that while some possible mechanisms for the formation of formamide (Redondo et al. 2014b) and glycine (Barrientos et al. 2012) should be discarded due to high reaction barriers, others are possible, like the formation of acetamide through $\mathrm{H}_{2} \mathrm{NCHO}+\mathrm{CH}_{5}^{+}$reaction (Redondo et al. 2014a) or formamide through a radical mechanism (Barone et al. 2015). Ion-molecule collisions 
were suggested as a possible mechanism in both experimental (Geppert \& Larsson 2013; Larsson et al. 2012; Blagojevic et al. 2003; Petrie \& Bohme 2007; Snow et al. 2007) and theoretical studies (Spezia et al. 2016). In this case even reactions with (small) activation barriers are possible thanks to the transformation in the collision of some of the translational energy into internal energy. Also gas-phase neutral-neutral reactions are a possible source of synthesis of carbon-bearing molecules (Kaiser 2012).

Another suggested way for the synthesis of these molecules is that they were formed on interstellar grains surface. One particularly studied case is ice, which can decrease the activation energy. For example, the formation of glycine (Holtom et al. 2005), amino acids (Elsila et al. 2007), dipeptides (Kaiser et al. 2013), hydroxyacetonitrile, aminomethanol and polyoxymethylene (Danger et al. 2012, 2014), glycolaldehyde and glyceraldehyde (de Marcellus et al. 2015), or alpha-aminoethanol (Duvernay et al. 2010) in ice was reported experimentally. Recently, Forstel et al. (2016) have synthesized urea in cometary model ices thanks to the irradiation of inorganic ice (which contains $\mathrm{CO}$ and $\mathrm{NH}_{3}$ ), proposing a mechanism in which $\mathrm{NH}_{2}$. is added to hydrogenated $\mathrm{CO}$.

In many cases, calculations have shown that the activation energies are reduced by the presence of water molecules (Woon 1999, 2001, 2002; Koch et al. 2008; Chen \& Woon 2011; Rimola et al. 2012). Even if the activation barriers were reduced, they are still generally too high to allow a thermal reaction at low temperature conditions; however, in some cases they are compatible with the observed abundances in low-mass protostars and dark cores (Rimola et al. 2014).

In the present work, we have studied, by highly correlated quantum chemistry calculations, the possibility of forming urea by three classes of gas-phase reactions: ion-molecule, neutralneutral, and radical. In the case of ion-molecule reaction, one tempting reactant to check is neutral and protonated hydroxylamine $\left(\mathrm{NH}_{2} \mathrm{OH}\right)$. In particular, the protonated form was suggested to be a possible precursor for the formation of glycine and formamide by ion-molecule collisions (Snow et al. 2007; Spezia et al. 2016), but the potential energy surfaces always have an activation barrier (Barrientos et al. 2012; Redondo et al. 2014b). Despite the neutral form not being observed in the ISM, its protonated species could be formed and just not detected, as suggested by Pulliam et al. (2012), who provided a clear picture of the non-detection of the neutral species suggesting the possibility of the existence of the protonated one. Our calculations have found that the $\mathrm{NH}_{2} \mathrm{OH}_{2}^{+}+\mathrm{H}_{2} \mathrm{NCHO}$ (formamide) reaction proceeds via a barrierless pathway, such that this is a plausible route for its synthesis under ISM conditions. We should note that $\mathrm{NH}_{2} \mathrm{OH}_{2}^{+}$is the high energy form of protonated hydroxylamine: calculations by Boulet et al. (1999) have shown that protonation of neutral $\mathrm{NH}_{2} \mathrm{OH}$ could provide both isomers $\left(\mathrm{NH}_{3} \mathrm{OH}^{+}\right.$ and $\mathrm{NH}_{2} \mathrm{OH}_{2}^{+}$), whose interconversion barrier is too high to be passed, so that the more reactive $\mathrm{NH}_{2} \mathrm{OH}_{2}^{+}$species can exist. Other reactions involving species observed in the ISM are also investigated but reactions proceed through non-negligible energy barriers. Finally we have studied the neutral-neutral reaction and the radical-molecule reaction. Both have reaction barriers that are too high.

The remainder of the article is as follows. The methods used are described in Sect. 2, results are then presented first in terms of the thermodynamics of the reactions investigated (Sect. 3.1) and then we detail the reaction pathways in terms of minima and transition states connecting reactants to products (Sects. 3.2, 3.3, and 3.4). Section 4 concludes.

\section{Computational details}

All structures (minima and transition states, TSs) were first optimized at the B3LYP/6-311++G(d, p) level of theory (Becke 1993; Lee et al. 1988), then, using these structures as starting points, we located minima and TSs using the MøllerPlesset level of theory (MP2) with aug-cc-pVTZ basis set (Dunning Jr. 1989; Davidson 1996). Finally, the electronic energies were calculated using the highly correlated coupled cluster method, CCSD(T) (Purvis III \& Bartlett 1982; Pople et al. 1987), with the same basis set. Energies are thus reported using the CCSD(T)/aug-cc-pVTZ electronic energy on the MP2/augcc-pVTZ minima and TSs. Zero point energy (ZPE) is calculated at the same MP2 level of theory. These results are thus labeled as CCSD(T)/aug-cc-pVTZ//MP2/aug-cc-pVTZ in the following. With structures of reactants and products, we calculated the energy differences taking into account the ZPE corrections and the Gibbs free energy differences at $15 \mathrm{~K}$ using standard thermochemistry and the harmonic frequencies (McQuarrie 1973).

To verify that the TSs correctly connect the minima identified in the potential energy surface (PES), we performed intrinsic reaction coordinate (IRC) calculations (Fukui 1981). All results show that the TSs correspond to the saddle point in the minimum energy path between two given minima (reactants, products and intermediates).

In the case of radical reactions, we considered the doublet spin multiplicity and verified that there is no spin contamination. We obtained $\langle S\rangle^{2}$ values very close to the theoretical one $(0.75)$ and, for two transition states that have values about $10 \%$ higher than the theoretical value, T1 diagnostics (Lee \& Taylor 1989) on CCSD(T) calculations were performed, providing very small values, thus strengthening our confidence in the calculation results.

Spontaneous emission rate constants were calculated using frequencies and Einstein coefficients obtained by ab initio calculations and using the method reported by Herbst (1982) with our in-house code. All quantum chemistry and thermochemistry calculations were performed using Gaussian 09 software (Frisch et al. 2009).

\section{Results}

\subsection{Thermodynamics}

We first considered the energetics in terms of $\Delta E$ including the ZPE effects and gas phase $\Delta G$ at $15 \mathrm{~K}$ of possible reactions leading to urea. In particular we took into account three classes of reactions, ion-molecule, neutral-neutral, and radical reactions. Results are summarized in Table 1. In Fig. 1 we show the structures of reactants and products considered here (we omitted simple products like $\mathrm{H} \cdot, \mathrm{H}_{2}, \mathrm{H}_{2} \mathrm{O}$, and $\mathrm{CH}_{4}$ ).

First, let us consider ion-molecule reactions. The most simple ones would be

$$
\begin{aligned}
& \mathrm{NH}_{3}+\mathrm{CONH}_{2}^{+} \rightarrow \mathrm{UreaH}^{+} \\
& \mathrm{NH}_{4}^{+}+\mathrm{HNCO} \rightarrow \mathrm{UreaH}^{+},
\end{aligned}
$$

which correspond to the condensation of $\mathrm{NH}_{3}$ with $\mathrm{CONH}_{2}^{+}$or $\mathrm{NH}_{4}^{+}$with $\mathrm{HNCO}$, both being exothermic. However, the urea eventually formed needs an environment to keep the excess energy or, alternatively, can be stabilized by spontaneous emission of a photon (corresponding to a radiative association reaction). In the gas phase, there is no environment to take the energy of the formed protonated urea, so there are two competing routes: (i) unimolecular dissociation and (ii) radiative decay. 
F. S. Brigiano et al.: The formation of urea in space. I.
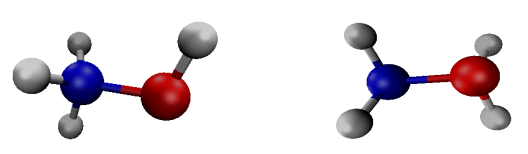

$\mathrm{NH}_{3} \mathrm{OH}^{+}$

$\mathrm{NH}_{2} \mathrm{OH}_{2}^{+}$
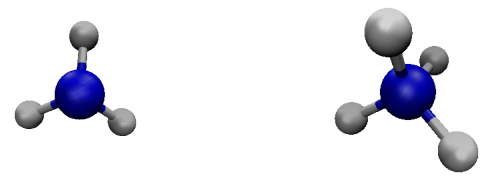

$\mathrm{NH}_{3}$

$\mathrm{NH}_{4}^{+}$
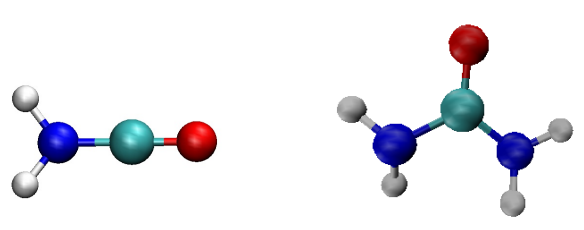

Urea

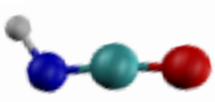

HNCO
$\mathrm{H}_{2} \mathrm{NCO}^{+}$

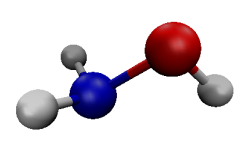

$\mathrm{NH}_{2} \mathrm{OH}$

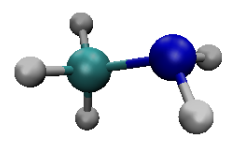

$\mathrm{CH}_{3} \mathrm{NH}_{2}$

$\mathrm{CH}_{3} \mathrm{NH}_{3}{ }^{+}$
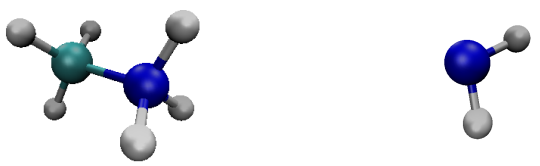

$\mathrm{NH}_{2}$

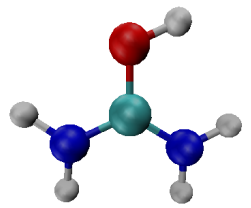

UreaH $^{+}$

Fig. 1. Structures of reactants and products considered (simple products like $\mathrm{H} \cdot \mathrm{H}_{2}, \mathrm{H}_{2} \mathrm{O}$, and $\mathrm{CH}_{4}$ are omitted). Oxygen atoms are in red, nitrogen in blue, carbon in cyan, and hydrogen in white.

Table 1. Energetics: $\Delta E$ with ZPE correction and $\Delta \mathrm{G}$ calculated at $15 \mathrm{~K}$ as obtained from MP2/aug-cc-pVTZ//CCSD(T)/aug-cc-pVTZ calculations.

\begin{tabular}{|c|c|c|c|c|}
\hline & Reaction & $\Delta E(\mathrm{kcal} / \mathrm{mol})$ & $\Delta G(\mathrm{kcal} / \mathrm{mol})$ & $E^{a}(\mathrm{kcal} / \mathrm{mol})$ \\
\hline & \multicolumn{4}{|l|}{ Ion-molecule } \\
\hline (1) & $\mathrm{NH}_{3}+\mathrm{CONH}_{2}^{+} \rightarrow \mathrm{UreaH}^{+}$ & -50.48 & -50.30 & $(-7.82)^{a}$ \\
\hline (2) & $\mathrm{NH}_{4}^{+}+\mathrm{HNCO}^{2} \rightarrow \mathrm{UreaH}^{+}$ & -20.31 & -20.14 & $(23.15)^{a}$ \\
\hline (3) & $\mathrm{NH}_{3}^{4} \mathrm{OH}^{+}+\mathrm{HCONH}_{2} \rightarrow \mathrm{UreaH}^{+}+\mathrm{H}_{2} \mathrm{O}$ & -71.60 & -70.10 & 17.60 \\
\hline (4) & $\mathrm{NH}_{2} \mathrm{OH}_{2}^{+}+\mathrm{HCONH}_{2} \rightarrow \mathrm{UreaH}^{+}+\mathrm{H}_{2} \mathrm{O}$ & -97.40 & -97.30 & -8.04 \\
\hline (5) & $\mathrm{NH}_{2} \mathrm{OH}+\mathrm{HCOHNH}_{2}^{+} \rightarrow \mathrm{UreaH}^{+}+\mathrm{H}_{2} \mathrm{O}$ & -70.49 & -70.40 & 18.80 \\
\hline (6) & $\mathrm{NH}_{4}^{+}+\mathrm{HCONH}_{2} \rightarrow$ UreaH $^{+}+\mathrm{H}_{2}$ & -4.89 & -4.73 & 85.18 \\
\hline (7) & $\mathrm{NH}_{3}^{4}+\mathrm{HCOHNH}_{2}^{+} \rightarrow \mathrm{UreaH}^{+}+\mathrm{H}_{2}$ & -12.41 & -12.26 & 77.66 \\
\hline (8) & $\mathrm{CH}_{3} \mathrm{NH}_{2}+\mathrm{HCOHNH}_{2}^{+} \rightarrow$ UreaH $^{+}+\mathrm{CH}_{4}$ & -35.47 & -35.44 & 70.58 \\
\hline \multirow[t]{2}{*}{ (9) } & $\mathrm{CH}_{3} \mathrm{NH}_{3}^{+}+\mathrm{HCONH}_{2} \rightarrow \mathrm{UreaH}^{+}+\mathrm{CH}_{4}$ & -16.94 & -16.89 & 89.13 \\
\hline & Neutral-neutral & & & \\
\hline$(10)$ & $\mathrm{NH}_{3}+\mathrm{HNCO} \rightarrow$ Urea & -14.78 & -14.64 & - \\
\hline (11) & $\mathrm{NH}_{2} \mathrm{OH}+\mathrm{HCONH}_{2} \rightarrow$ Urea $+\mathrm{H}_{2} \mathrm{O}$ & -57.46 & -57.38 & 60.26 \\
\hline (12) & $\mathrm{NH}_{3}+\mathrm{HCONH}_{2} \rightarrow$ Urea $+\mathrm{H}_{2}$ & 0.61 & 0.75 & - \\
\hline \multirow[t]{2}{*}{ (13) } & $\mathrm{CH}_{3} \mathrm{NH}_{2}+\mathrm{HCONH}_{2} \rightarrow$ Urea $+\mathrm{CH}_{4}$ & -22.44 & -22.79 & - \\
\hline & Radical & & & \\
\hline (14) & $\mathrm{NH}_{2} \cdot+\mathrm{HCONH}_{2} \rightarrow$ Urea $+\mathrm{H} \cdot$ & -1.84 & -1.65 & 16.22 \\
\hline (15) & $\mathrm{NH}_{3}+\mathrm{HCONH} \cdot \rightarrow$ Urea $+\mathrm{H}$ & -11.76 & -11.65 & 6.18 \\
\hline
\end{tabular}

Notes. Activation energies, $E^{a}$ (with ZPE correction), as obtained at the same level of theory for the different path investigated are shown. When a pathway was not characterized (see text) it is marked with -. For UreaH ${ }^{+}$we report the energy formation for the most stable isomer. ${ }^{(a)}$ Values as from Spezia et al. (2009). 
The rate constants for the unimolecular dissociation of protonated urea were previously reported by Spezia et al. (2009) and they are, for energies in 40-300 kcal/mol range, in the ps-ns timescale. Spontaneous emission rate constants are an order of magnitude larger (between 40 and $650 \mathrm{~s}^{-1}$ in the same energy range), suggesting that it is unlikely that the urea would be stabilized in this way. We should note that this same previous work reported that the $\mathrm{NH}_{3}+\mathrm{CONH}_{2}^{+}$reaction channel would be barrierless (the original study focused on the unimolecular decomposition of protonated urea).

We now consider ion-molecule reactions, which produce two products, such that the final relative translational energy can take the excess energy and stabilize the products. First, in analogy with reactions proposed for the gas-phase bimolecular synthesis of formamide (Redondo et al. 2014b) and glycine (Barrientos et al. 2012), we have considered the following reactions

$$
\begin{aligned}
& \mathrm{NH}_{3} \mathrm{OH}^{+}+\mathrm{HCONH}_{2} \rightarrow \mathrm{UreaH}^{+}+\mathrm{H}_{2} \mathrm{O} \\
& \mathrm{NH}_{2} \mathrm{OH}_{2}^{+}+\mathrm{HCONH}_{2} \rightarrow \mathrm{UreaH}^{+}+\mathrm{H}_{2} \mathrm{O} \\
& \mathrm{NH}_{2} \mathrm{OH}+\mathrm{HCOHNH}_{2}^{+} \rightarrow \mathrm{UreaH}^{+}+\mathrm{H}_{2} \mathrm{O} .
\end{aligned}
$$

All of them are strongly exothermic and exergonic, so we better investigated the corresponding PES to obtain information on the barrier energies. These PESs are reported in Sect. 3.2.

We have also considered reactions between $\mathrm{NH}_{3}, \mathrm{HCONH}_{2}$, and $\mathrm{CH}_{3} \mathrm{NH}_{2}$, considering in each case a neutral and a protonated species:

$$
\begin{aligned}
& \mathrm{NH}_{4}^{+}+\mathrm{HCONH}_{2} \rightarrow \mathrm{UreaH}^{+}+\mathrm{H}_{2} \\
& \mathrm{NH}_{3}+\mathrm{HCOHNH}_{2}^{+} \rightarrow \mathrm{UreaH}^{+}+\mathrm{H}_{2} \\
& \mathrm{CH}_{3} \mathrm{NH}_{2}+\mathrm{HCOHNH}_{2}^{+} \rightarrow \mathrm{UreaH}^{+}+\mathrm{CH}_{4} \\
& \mathrm{CH}_{3} \mathrm{NH}_{3}^{+}+\mathrm{HCONH}_{2} \rightarrow \mathrm{UreaH}^{+}+\mathrm{CH}_{4} .
\end{aligned}
$$

$\mathrm{NH}_{3}$ (ammonia), $\mathrm{HCONH}_{2}$ (formamide), and $\mathrm{CH}_{3} \mathrm{NH}_{2}$ (methylamine) were observed in the ISM by Cheung et al. (1968), Rubin et al. (1971), Kaifu et al. (1974); Fourikis et al. (1974), respectively, so they should be considered as possible reactants. Protonated ammonia, $\mathrm{NH}_{4}^{+}$, cannot be observed for symmetry reasons, but recently the observation of the $\mathrm{NH}_{3} \mathrm{D}^{+}$isotope was reported by Cernicharo et al. (2013), strengthening the possibilities of the existence of $\mathrm{NH}_{4}^{+}$in the ISM. Also in this case, all the corresponding reactions are exothermic and exergonic, while the energy and free energy differences are smaller than for reactions 3-5. It is worth investigating the PES also for those reactions in order to localize the barrier energies.

We then considered the following neutral-neutral reactions:

$\mathrm{NH}_{3}+\mathrm{HNCO} \rightarrow$ Urea

$$
\begin{aligned}
& \mathrm{NH}_{2} \mathrm{OH}+\mathrm{HCONH}_{2} \rightarrow \text { Urea }+\mathrm{H}_{2} \mathrm{O} \\
& \mathrm{NH}_{3}+\mathrm{HCONH}_{2} \rightarrow \text { Urea }+\mathrm{H}_{2} \\
& \mathrm{CH}_{3} \mathrm{NH}_{2}+\mathrm{HCONH}_{2} \rightarrow \text { Urea }+\mathrm{CH}_{4} .
\end{aligned}
$$

Reaction 10 is exothermic and exergonic, but in the gas phase it also has the problem of stabilization by radiative emission. The radiative emission rate constant is in the $40-350 \mathrm{~s}^{-1}$ range for energies in the $40-300 \mathrm{kcal} / \mathrm{mol}$ range, similar to protonated urea values, suggesting that it would be easier to dissociate back to reactants than to stabilize the products by emitting infra-red light. We thus do not follow this reaction. Reaction 12 is slightly endothermic and endergonic and thus the barrier will also be positive, and thus we did not study the details of the corresponding PES. Finally, reactions 11 and 13 are exothermic and exergonic, even if, as expected, less so than corresponding ion-molecule reactions. Generally, barriers for neutral-neutral reactions are higher (and positive) than corresponding ion-molecule reactions, because in the latter the electrostatic barrier corresponding to the approaching of the reactants is lowered by ion-dipole attraction, while in neutral-neutral, weaker dipole-dipole interactions have a negative contribution to the interaction (Levine 2005). We will show the PES of the most exothermic and exergonic reaction 11 in order to have information on the barrier in Sect. 3.3.

Finally, inspired by the recent work by Barone et al. (2015) on formamide, we studied two simple radical reactions:

$$
\begin{aligned}
& \mathrm{NH}_{2} \cdot+\mathrm{HCONH}_{2} \rightarrow \text { Urea }+\mathrm{H} \\
& \mathrm{NH}_{3}+\mathrm{HCONH} \cdot \rightarrow \text { Urea }+\mathrm{H} .
\end{aligned}
$$

Also in this case the reactions are exothermic and exergonic, while values are smaller than ion-molecule reactions 3-5, but also smaller than the neutral-neutral reaction 11 . We will study the PES associated to these radical reaction in Sect. 3.4.

To conclude, almost all the reactions reported have a favorable thermochemistry, such that it will be worth investigating for most of them the details of the PES in order to locate the corresponding barriers. We should note that in both ionmolecule and neutral-neutral reactions, the ones in which a water molecule is formed have the most negative energy and free energy, similarly to what has been reported in previous studies of formamide (Redondo et al. 2014b) and glycine (Snow et al. 2007; Barrientos et al. 2012).

\subsection{Mechanisms for ion-molecule reactions}

We now report the PES in terms of connected minima and TSs for the ion-molecule reactions considered previously. First, we start with reactions 3-5, which are responsible for the formation of protonated urea and neutral water, reaction 4 being in particular the most thermodynamically favored among all the reactions considered in the present work. As we will see, it transpires that this last has a reaction channel leading to the formation of protonated urea (and not only), which is barrierless. The reaction pathway diagram is shown in Fig. 2. Investigating in more detail this pathway, we can observe that the interaction between $\mathrm{NH}_{2} \mathrm{OH}_{2}^{+}$with $\mathrm{HCONH}_{2}$ leads to the formation of the complex I3A, which shows a hydrogen bond between the carbonyl oxygen of formamide and the hydrogen atom of the amine group of protonated hydroxylamine. This complex I3A can then evolve to the I4A intermediate through the transition state TS3A that represents the highest energy barrier $(-8.04 \mathrm{kcal} / \mathrm{mol}$ with respect to reactants) of this reaction pathway. The mechanism that leads to I4A implies the electrophilic attack of the amino group of hydroxylamine to the amino group of formamide. This results in a simultaneous formation of a N-N bond and in the cleavage of the $\mathrm{N}-\mathrm{O}$ bond with consequent formation of a water molecule. We should note that to form I4A, the system has to pass the TS3A barrier, which is higher in energy than the exit channel leading to $\mathrm{NH}_{3} \mathrm{OH}^{+}+\mathrm{HCONH}_{2}$ and $\mathrm{NH}_{2} \mathrm{OH}+\mathrm{HCOHNH}_{2}^{+}$products, shown as asymptotic lines in Fig. 2. The system has thus different possibilities and the branching ratio will depend on the dynamical evolution of I3A. If a purely statistical kinetic regime will hold, then the exit channels will be likely favored, but a fraction of trajectories would be able to pass the TS3A, forming I4A. 


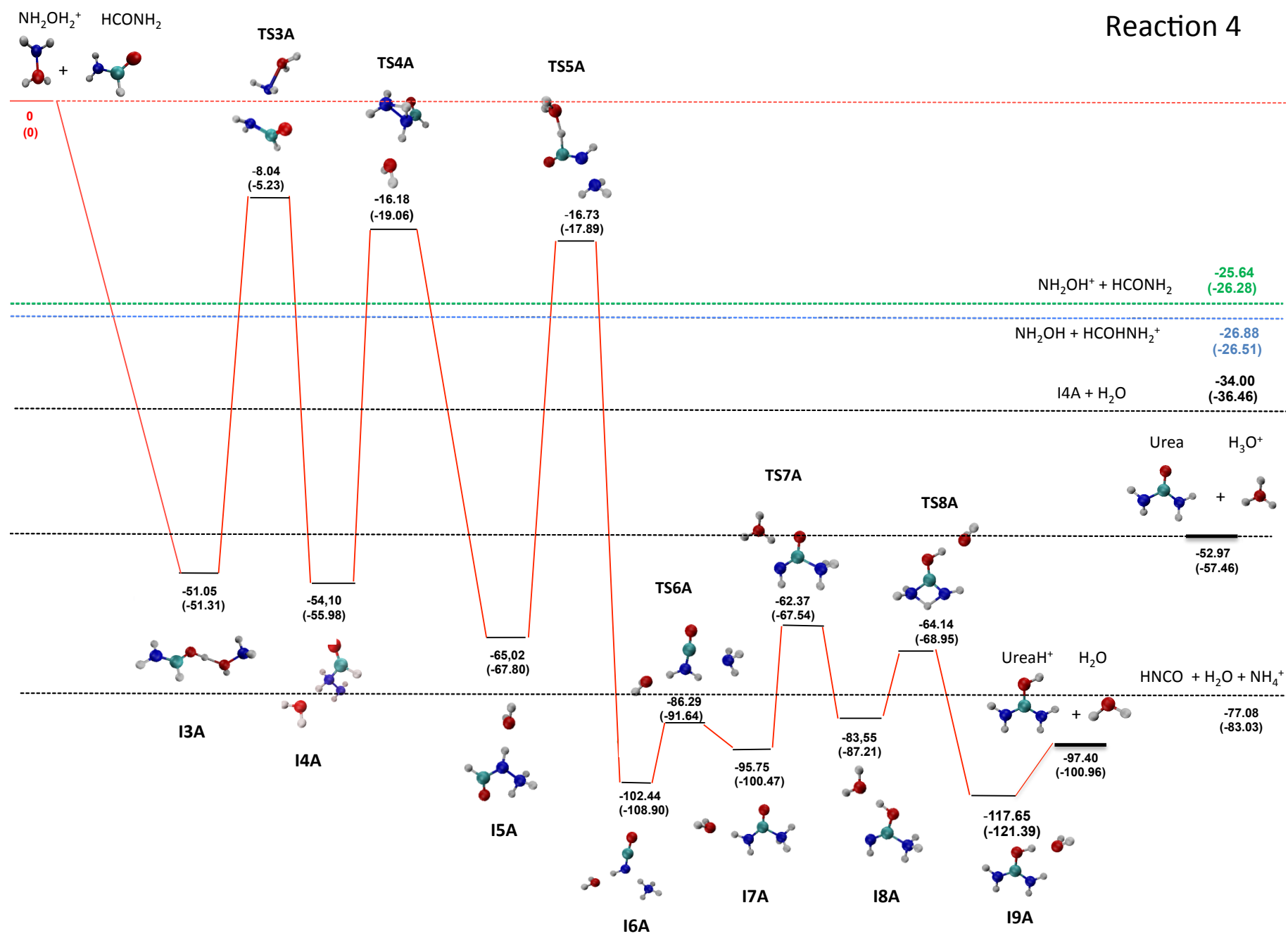

Fig. 2. Energy profiles, in kcal/mol, for the ion-molecule reaction $\mathrm{NH}_{2} \mathrm{OH}_{2}^{+}+\mathrm{HCONH}_{2}$, as obtained by CCSD(T)/aug-cc-pVTZ//MP2-aug-ccpVTZ and MP2/aug-cc-pVTZ (in parenthesis) calculations. These values contain zero-point energies (ZPE). In the final step we report the energy of the cluster, the final product energy being reported in Table 1 .

Dynamical calculations will be useful in the future to better understand this aspect.

If I4A intermediate is obtained then it can evolve to I5A through hydrogen migration from the secondary to the primary amino group, through TS4A. The barrier of this and the following TSs is lower than the previous one (TS3A). The concerted mechanism, responsible for the formation of I6A through TS5A, involves the hydrogen abstraction reaction of the $\mathrm{C}$ atom by the water molecule and the simultaneous cleavage of the $\mathrm{N}-\mathrm{N}$ bond. This mechanism leads to the formation of I6A, a cluster made by isocyanic acid, protonated ammonia, and water. We should note that all these three species have been detected in the Sgr B2 cloud (Cheung et al. 1969; Snyder \& Buhl 1972); in the case of ammonium, the isotope $\mathrm{NH}_{3} \mathrm{D}^{+}$was detected by Cernicharo et al. (2013). It is thus possible that this cluster breaks into its constituents, being a possible barrierless pathway also for the formation of neutral isocyanic acid. In fact, the energy of the three separated species is $-77.08 \mathrm{kcal} / \mathrm{mol}$ with respect to reactants (see the asymptotic line in Fig. 2), such that the I6A needs only $25.36 \mathrm{kcal} / \mathrm{mol}$ to break into these pieces, which is comparable with the energy needed to pass the TSs and obtain protonated urea $+\mathrm{H}_{2} \mathrm{O}$.

From I6A the formation of the more stable isomer of protonated urea takes place through a three-step mechanism. In the first step, the hydrogen abstraction reaction of the ammonium ion by the imino group of the isocyanic acid induces the nucleophilic attack of the ammonia to the isocyanic carbon atom, leading to the formation of N-protonated urea through TS6A. In the second step, the hydrogen migration, assisted by water which becomes hydronium ion, $\mathrm{H}_{3} \mathrm{O}^{+}$, in the transition state TS7A from the amino-group of $\mathrm{N}$-protonated urea to its oxygen atom, produces I8A. In the third step, the more stable isomer of protonated urea is produced from I8A through the transition state TS8A, where a hydrogen migration takes place.

We should note that TS7A is actually a cluster composed of $\mathrm{H}_{3} \mathrm{O}^{+}$and an isomer of neutral urea. The products urea $+\mathrm{H}_{3} \mathrm{O}^{+}$ are $52.97 \mathrm{kcal} / \mathrm{mol}$ more stable than $\mathrm{NH}_{2} \mathrm{OH}_{2}^{+}+\mathrm{HCONH}_{2}$ reactants (see the corresponding asymptotic line in Fig. 2) and the system has thus enough energy to take a different path instead of the minimum energy path connecting TS7A to I8A (and then to $\mathrm{UreaH}^{+}+\mathrm{H}_{2} \mathrm{O}$ ), thus forming neutral urea. However, when optimizing the neutral $\mathrm{HNCONH}_{3}$ species of TS7A, we obtained spontaneously isocyanic acid (HNCO) and ammonia. The structures of relevant intermediates and transition states along this pathway are reported in Fig. 3.

The PESs for reactions 3 and 5 show a positive and high activation energy and the corresponding diagrams are reported in Fig. A.1 as Path A and B, respectively. The corresponding 


\section{$\underline{\text { Intermediates }}$}

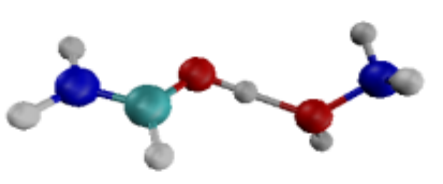

I3A

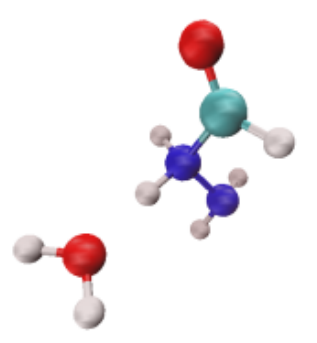

$14 \mathrm{~A}$

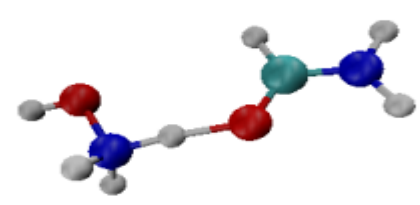

$11 \mathrm{~A}$

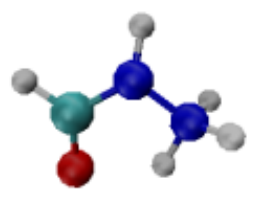

I5A

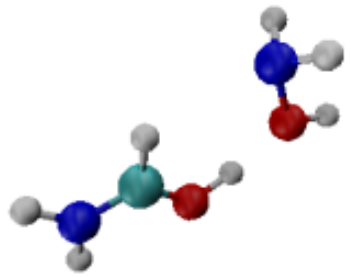

I2A

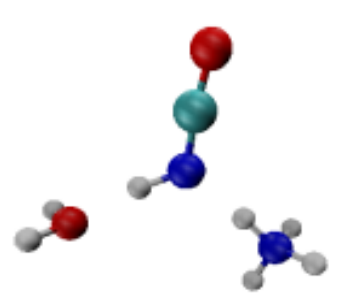

$16 \mathrm{~A}$

\section{Transition states}

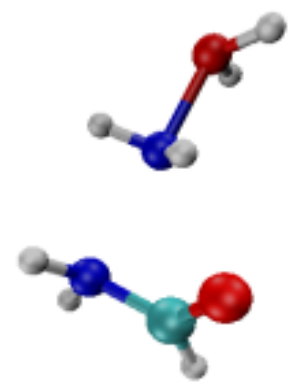

TS3A

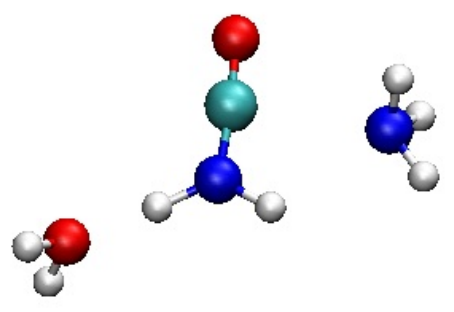

TS6A

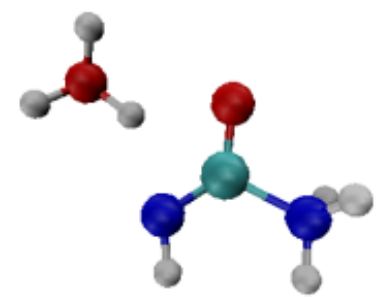

TS7A

Fig. 3. Structures of most relevant intermediates and transition states as obtained from reactions 3, 4, and 5. Oxygen atoms are in red, nitrogen in blue, carbon in cyan, and hydrogen in white.

barriers of 17.6 and $18.8 \mathrm{kcal} / \mathrm{mol}$ for Path $\mathrm{A}$ and $\mathrm{B}$, respectively, make the two reactions impossible under low temperature conditions. Details are given in Appendix A.1.

The results of our PES analysis show that only the reaction involving the less stable isomer of protonated hydroxylamine, $\mathrm{NH}_{2} \mathrm{OH}_{2}^{+}$, with neutral formamide, $\mathrm{HCONH}_{2}$, leads to urea through a barrierless pathway. This same pathway can be responsible for the formation of isocyanic acid, which was found as an intermediate of the full pathway. Of course, once the I3A complex is formed from a $\mathrm{NH}_{2} \mathrm{OH}_{2}^{+}+\mathrm{HCONH}_{2}$ reaction, it can evolve, forming protonated urea via TS3A or isomerizing into $\mathrm{I} 2 \mathrm{~A}$ and $\mathrm{I} 1 \mathrm{~A}$, in this case reacting back and forming $\mathrm{NH}_{3} \mathrm{OH}^{+}+\mathrm{HCONH}_{2}$ or $\mathrm{NH}_{2} \mathrm{OH}+\mathrm{HCOHNH}_{2}^{+}$.

An estimate of the ratio of the two reaction channels can be obtained from the RRKM rate constant to pass the TS3A $\left(k^{\mathrm{TS} 3 \mathrm{~A}}\right)$ versus TS2A $\left(k^{\mathrm{TS} 2 \mathrm{~A}}\right)$ transition states, as shown in Fig. 4. The evolution of the rate constant ratio as a function of internal energy shows that, while for low energy values the pathway initiated by the TS2A isomer is dominant, the other pathway becomes increasingly important as the internal energy of the intermediate increases, with a ratio close to one at higher

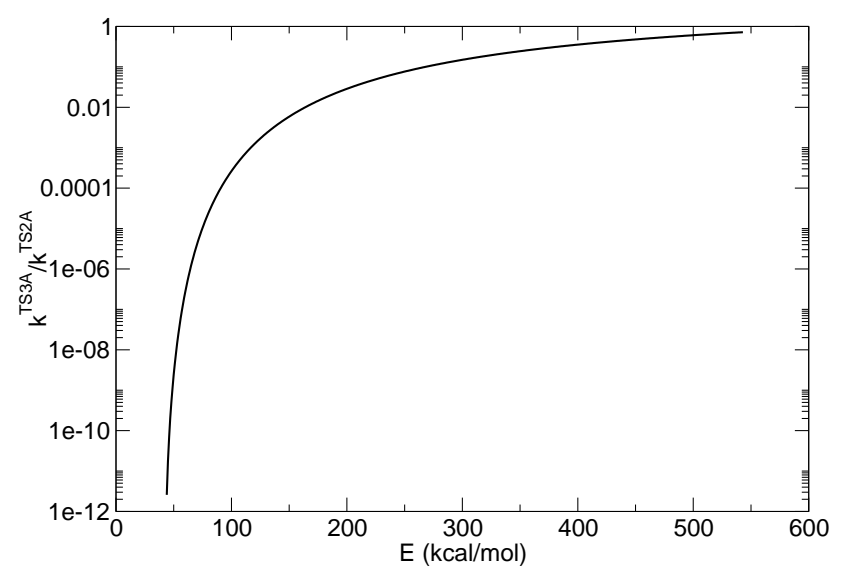

Fig. 4. Ratio between $k^{T S 3 A}$ and $k^{T S 2 A}$ rate constants corresponding to the activation of I3A complex as function of its internal energy $(E)$.

energies. Of course, this is a simple picture that does not take into account the dynamical effect related to the collision between 


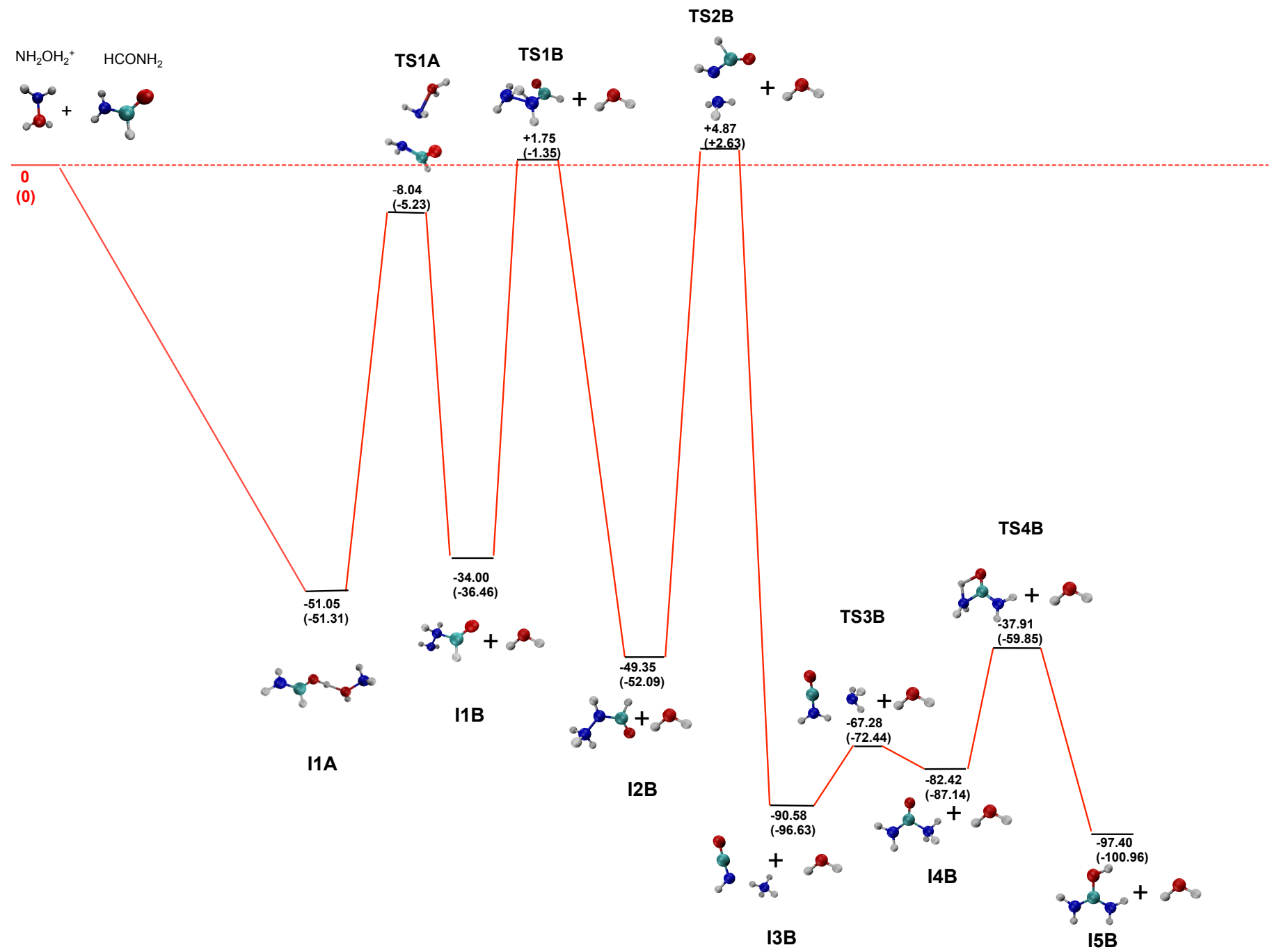

Fig. 5. Energy profile, in kcal/mol, for ion-molecule reaction $\mathrm{NH}_{2} \mathrm{OH}_{2}^{+}+\mathrm{HCONH}_{2}$ in which water molecule was separated from ion once formed, as obtained by CCSD(T)/aug-cc-pVTZ//MP2-aug-cc-pVTZ and MP2/aug-cc-pVTZ (in parenthesis) calculations. These values contain zero-point energies (ZPE).

$\mathrm{NH}_{2} \mathrm{OH}_{2}^{+}$and $\mathrm{HCONH}_{2}$, and a more detailed study of such reactive scattering events would shed more light on the competition between the different pathways. In conclusion, both neutral isocyanic acid and protonated urea can be formed from a $\mathrm{NH}_{2} \mathrm{OH}_{2}^{+}+\mathrm{HCONH}_{2}$ reaction under the ISM conditions, even if their formation will be in competition with the formation of $\mathrm{NH}_{3} \mathrm{OH}^{+}+\mathrm{HCONH}_{2}$ and $\mathrm{NH}_{2} \mathrm{OH}+\mathrm{HCOHNH}_{2}^{+}$products.

Finally, we investigated the key role of the water molecule in the previously discussed pathway. To this end, we calculated minima and TSs removing the $\mathrm{H}_{2} \mathrm{O}$ (i.e., calculating separately the energies of the ions and the neutral water molecule) following its formation from intermediate I2B (before the mechanism is by definition the same) up to the final products. Results are shown in Fig. 5. In the absence of the water molecule, the energy of minima and (more importantly) TSs increases, such that the reaction has a net activation barrier of $4.87 \mathrm{kcal} / \mathrm{mol}$. The stability of ion-water clusters during the reaction path is thus crucial, the water molecule acting somehow as a catalyzer in the reaction.

We now consider reactions 6 and 7, involving formamide and ammonia (neutral and protonated). The PES leading to the formation of protonated urea and $\mathrm{H}_{2}$ is shown in Fig. A.2. The two paths identified have a positive barrier of 85.18 and $77.66 \mathrm{kcal} / \mathrm{mol}$, respectively, and thus they can be disregarded as possible pathways for the formation of urea in the ISM. Details are given in Appendix A.1.

We finally move to ion-molecule reactions 8 and 9 involving methylamine and formamide. These reactions are also potentially very interesting since the neutral species of both reactants and products were all detected in the ISM (Kaifu et al. 1974; Remijan et al. 2014; Rubin et al. 1971; Lacy et al. 1991). In Fig. A.3 we report the PES of the two pathways, which have positive barriers of 70.58 and $89.13 \mathrm{kcal} / \mathrm{mol}$, respectively. Thus, despite the high exothermicity of reaction $8(\Delta E=$ $-35.47 \mathrm{kcal} / \mathrm{mol}$ ), it is not likely to occur in the ISM due to the high activation energy barrier. We discuss details of these pathways in Appendix A.1.

To summarize, the only ion-molecule reaction that shows a barrierless pathway for the synthesis of protonated urea is reaction 4, which has as reactant the high energy protonated hydroxyl amine $\left(\mathrm{NH}_{2} \mathrm{OH}_{2}^{+}\right)$. The same reaction can also lead to neutral isocyanic acid.

\subsection{Mechanisms for neutral-neutral reactions}

We now consider the PES connecting reactants and products for neutral-neutral reaction 11 , which is the most exothermic 
and exergonic reaction. In this case, we found two different pathways, shown in Fig. A.4, whose energetic is very similar, both with a positive barrier $(61.59$ and $60.26 \mathrm{kcal} / \mathrm{mol}$ for Path A and B, respectively). These barriers make the reaction unlikely under ISM conditions and details are thus discussed in Appendix A.2.

\subsection{Mechanisms for radical reactions}

Finally, we consider the PES of the two radical reactions 14 and 15, which are shown in Fig. A.5 (Path A and B, respectively). Both reactions occur on a doublet potential energy surface, which is conserved through the reaction. The resulting activation energies are of 16.22 and $6.18 \mathrm{kcal} / \mathrm{mol}$, being too high for thermal reactivity in the ISM. Details of the PES of these reactions are thus reported in Appendix A.3.

\section{Conclusions and outlooks}

In this work we have investigated, by highly correlated quantum chemistry calculations, the thermodynamic and kinetic possibility of forming urea in ISM conditions through ion-molecule, neutral-neutral, and radical reactions. Recently a tentative detection of urea in the ISM was reported by Remijan et al. (2014) and this is the first quantum chemistry study devoted to understanding possible gas-phase reactions concerning the formation of this molecule, while a recent theoretical chemistry study relevant to the astrophysical presence of urea considered the stability of different urea isomers, concluding that the $\left(\mathrm{NH}_{2}\right)_{2} \mathrm{CO}$ form is the one likely to be observed in the ISM (Fourré et al. 2016).

We have summarized in Table 1 the activation energies, $E^{a}$, of the different pathways chosen on the basis of our calculations - here we consider as $E^{a}$ the energy difference between the reactants and the transition state highest in energy along the given pathway. Only the reaction between $\mathrm{NH}_{2} \mathrm{OH}_{2}^{+}$(the high energy tautomer of protonated hydroxylamine) and formamide is possible through a barrierless mechanism, suggesting the possibility of this happening in the ISM. The $\mathrm{NH}_{2} \mathrm{OH}_{2}^{+}$reactant, thus, seems to be a key species, since it was also suggested to be a reactant for the formation of formamide in a recent ionmolecule collisional study (Spezia et al. 2016). In line with what has been suggested by Pulliam et al. (2012), who reported the non-observation of neutral hydroxylamine, it is possible that the protonated species is present in the ISM.

Protonated urea can give neutral urea via a typical dissociative recombination reaction:

$\mathrm{UreaH}^{+}+\mathrm{e}^{-} \rightarrow \mathrm{Urea}+\mathrm{H}$.

Of course, the addition of one electron to protonated urea can lead also to different fragmentation products of the neutral radical species formed. This structure, however, is a (local) minimum, as reported by MP2 geometry optimization, and to further react, losing $\mathrm{H} \cdot$ or other species, it will need energy and thus it will depend on the internal energy of the molecules.

Another way of forming neutral urea would be by proton exchange with a species, $\mathrm{X}$, with higher proton affinity (PA):

$\mathrm{UreaH}^{+}+\mathrm{X} \rightarrow$ Urea $+\mathrm{HX}^{+}$.

The PA of urea was determined experimentally by Zheng \& Cooks (2002) to be $868.4 \pm 2.5 \mathrm{~kJ} / \mathrm{mol}$, and our calculations report a value of $868.4 \mathrm{~kJ} / \mathrm{mol}$ at $15 \mathrm{~K}$ and $862.5 \mathrm{~kJ} / \mathrm{mol}$ at $298 \mathrm{~K}$, which is in good agreement with the experimental determination. This value of PA is relatively high with respect to values known for molecules present in Sgr B2 (data are summarized in Table B.1), so that only few species, like cyclopropenylidene $(\mathrm{PA}=915.1 \mathrm{~kJ} / \mathrm{mol})$, iron oxide $(\mathrm{PA}=907 \mathrm{~kJ} / \mathrm{mol})$, methylamine $(\mathrm{PA}=899 \mathrm{~kJ} / \mathrm{mol})$, ethanimine $(\mathrm{PA}=884.6 \mathrm{~kJ} / \mathrm{mol})$, and $\mathrm{C}_{2} \mathrm{~S}(\mathrm{PA}=869.6 \mathrm{~kJ} / \mathrm{mol})$ are compatible with a proton transfer reaction from protonated urea.

Furthermore, we have pointed out that the barrierless mechanism needs the $\mathrm{H}_{2} \mathrm{O}$ water molecule, once formed before the ion isomerizes to the urea structure, to stay close to this ion in order to decrease the proton transfer barriers. While the present calculations are done in the gas phase, this result could be a suggestion to study the role of catalytic ice on these reactions, which could largely favor the reactivity, as pointed out from calculations studying the synthesis of other species (Woon 1999, 2001, 2002; Koch et al. 2008; Chen \& Woon 2011; Rimola et al. 2012, 2014). Finally, we should note that the same reaction pathway responsible for the formation of protonated urea can also lead to isocyanic acid (here directly the neutral form), which was also observed in the ISM (Snyder \& Buhl 1972); structures of this part of the PES can also lead to $\mathrm{H}_{3} \mathrm{O}^{+}$and neutral urea, while the isomer is not stable and, in our static calculations, spontaneously formed isocyanic acid and ammonia.

Dynamical-based calculations would be interesting for future works to better elucidate some possible competing reaction pathways, in particular for the $\mathrm{NH}_{2} \mathrm{OH}_{2}^{+}+\mathrm{HCONH}_{2}$ reaction in which the barrierless formation of protonated urea is in competition with simple proton transfers forming $\mathrm{NH}_{2} \mathrm{OH}+\mathrm{HCOHNH}_{2}^{+}$ or $\mathrm{NH}_{3} \mathrm{OH}^{+}+\mathrm{HCONH}_{2}$. Other reactions show a too high energy barrier such that they should be disregarded. In conclusion, quantum chemistry calculations show that it would be possible that protonated urea is formed via an ion-molecule reaction under ISM conditions; then the neutral form can be finally obtained via a typical dissociative recombination reaction or from proton transfer to a molecule with higher proton affinity.

Acknowledgements. R.S. and Y.J. thank ANR DynBioReact (Grant No. ANR-14-CE06-0029-01) for support and CNRS program INFINITI (project ASTROCOL) for partial support. R.S. thanks Universidad de Valladolid for an invited professor fellowship.

\section{References}

Altwegg, K., Balsiger, H., Bar-Nun, A., et al. 2016, Science Adv., 2

Barone, V., Latouche, C., Skouteris, D., et al. 2015, MNRAS, 453, L31

Barrientos, C., Redondo, P., Largo, L., Rayon, V. M., \& Largo, A. 2012, ApJ, 748, 99

Becke, A. D. 1993, J. Chem. Phys., 98, 5648

Belloche, A., Menten, K. M., Comito, C., et al. 2008, A\&A, 482, 179

Belloche, A., Meshcheryakov, A. A., Garrod, R. T., et al. 2017, A\&A, 601, A49 Blagojevic, V., Petrie, S., \& Bohme, D. K. 2003, MNRAS, 339, L7

Boulet, P., Gilardoni, F., Weber, J., Chermette, H., \& Ellinger, Y. 1999, Chem. Phys., 244, 163

Cernicharo, J., Kahane, C., Guelin, M., \& Gomez-Gonzalez, J. 1988, A\&A, 189, L1

Cernicharo, J., Tercero, B., Fuente, A., et al. 2013, ApJ, 771, L10

Chen, L., \& Woon, D. E. 2011, J. Phys. Chem. A, 115, 5166

Cheung, A. C., Rank, D. M., Townes, C. H., Thornton, D. D., \& Welch, W. J. 1968, Phys. Rev. Lett., 21, 1701

Cheung, A., Rank, D. M., Townes, C., Thornton, D. D., \& Welch, W. 1969, Nature, 221, 626

Danger, G., Duvernay, F., P., T., Borget, F., \& Chiavassa, T. 2012, ApJ, 756, 11

Danger, G., Rimola, A., Mrad, N. A., et al. 2014, Phys. Chem. Chem. Phys., 16, 3360

Davidson, E. R. 1996, Chem. Phys. Lett., 260, 514

de Marcellus, P., Meinert, C., Myrgorodska, I., et al. 2015, PNAS, 112, 965

Dunning Jr., T. H. 1989, J. Chem. Phys., 90, 1007

Duvernay, F., Dufauret, V., Danger, G., et al. 2010, A\&A, 523, A79

Elsila, J. A., Dworkin, J. P., Bernstein, M. P., Martin, M. P., \& Sandford, S. A. 2007, ApJ, 660, 911 
F. S. Brigiano et al.: The formation of urea in space. I.

Forstel, A., Maksytenko, P., Jones, B. M., et al. 2016, Chem. Commun., 52, 741 Fourikis, N., Takagi, K., \& Morimoto, M. 1974, ApJ, 191, L139

Fourré, I., Rosset, L., Chevreau, H., \& Y. Ellinger, Y. 2016, A\&A, 589, A18 Frisch, M. J., Trucks, G. W., Schlegel, H. B., et al. 2009, Gaussian 09, Revision D.01

Fukui, K. 1981, Acc. Chem. Res., 81, 363

Geppert, W. D., \& Larsson, M. 2013, Chem. Rev., 113, 8872

Goesmann, F., Rosenbauer, H., Bredehöft, J. H., et al. 2015, Science, 349, aab0689

Gratier, P., Pety, J., Guzmán, V., et al. 2013, A\&A, 557, A101

Gupta, H., Gottlieb, C. A., Lattanzi, V., Pearson, J. C., \& McCarthy, M. C. 2013, ApJ, 778, L1

Hayats, R., Studier, M. H., Moore, L. P., \& Anders, E. 1975, Geochim. Cosmochim. Acta, 39, 471

Herbst, E. 1982, Chem. Phys., 65, 185

Hollis, J. M., Lovas, F. J., Remijan, A. J., et al. 2006, ApJ, 643, L25

Holtom, P. D., Bennet, C. J., Osamura, Y., Mason, N. J., \& Kaiser, R. I. 2005 ApJ, 626, 940

Hunter, E. P., \& Lias, S. G. 1998, J. Phys. Chem. Ref. Data, 27, 413

Kaifu, N., Morimoto, M., Nagane, K., et al. 1974, ApJ, 191, L135

Kaiser, R. I. 2012, Chem. Rev., 102, 1309

Kaiser, R. I., Stockton, A. M., Kim, Y. S., Jensen, E. C., \& Mathies, R. A. 2013 ApJ, 765, 111

Koch, D. M., Toubin, C., Peslherbe, G. H., \& Hynes, J. T. 2008, J. Phys. Chem. C, 112, 2972

Kolb, V. M. 2014, Astrobiology: An Evolutionary Approach (CRC Press)

Lacy, J., Carr, J., Evans, N. J., et al. 1991, ApJ, 376, 556

Larsson, M., Geppert, W. D., \& Nyman, G. 2012, Rep. Prog. Phys., 75, 066901

Lee, T. J., \& Taylor, P. R. 1989, Int. J. Quantum Chem., Quant. Chem. Symp., S23, 199
Lee, C., Yang, W., \& Parr, R. G. 1988, Phys. Rev. B, 88, 785 Levine, R. D. 2005, Molecular Reaction Dynamics (Cambridge University Press) McQuarrie, D. A. 1973, Statistical Thermodynamics (Harper and Row), 4

Petrie, S., \& Bohme, D. K. 2007, Mass Spec. Rev., 26, 258

Pople, J. A., Head-Gordon, M., \& Raghavachari, K. 1987, J. Chem. Phys., 87, 5968

Pulliam, R. L., McGuire, B. A., \& Remijan, A. J. 2012, ApJ, 751, 1

Purvis III, G. D., \& Bartlett, R. J. 1982, J. Chem. Phys., 76, 1910

Raunier, S., Chiavassa, T., Duvernay, F., et al. 2004, A\&A, 416, 165

Redondo, P., Barrientos, C., \& Largo, A. 2014a, ApJ, 793, 32

Redondo, P., Barrientos, C., \& Largo, A. 2014b, ApJ, 780, 181

Remijan, A. J., Hollis, J. M., Lovas, F. J., et al. 2008, ApJ, 675, L85

Remijan, A. J., Snyder, L. E., McGuire, B. A., et al. 2014, ApJ, 783, 77

Rimola, A., Sodupe, M., \& Ugliengo, P. 2012, ApJ, 754, 24

Rimola, A., Taquet, V., Ugliengo, P., Balucani, N., \& Ceccarelli, C. 2014, A\&A, 572, A70

Rubin, R., Swenson Jr, G., Benson, R., Tigelaar, H., \& Flygare, W. 1971, ApJ, 169 , L39

Snow, J. L., Orlova, G., Blagojevic, V., \& Bohme, D. K. 2007, J. Am. Chem. Soc., 129, 9910

Snyder, L. E., \& Buhl, D. 1972, ApJ, 177, 619

Spezia, R., Salpin, J.-Y., Gaigeot, M.-P., Hase, W. L., \& K., S. 2009, J. Phys. Chem. A, 113, 13853

Spezia, R., Jeanvoine, Y., Hase, W. L., Song, K., \& Largo, A. 2016, ApJ, 826, 107

Turner, B. E., Liszt, H. S., Kaifu, N., \& Kisliakov, A. G. 1975, ApJ, 201, L149

Woon, D. E. 1999, Icarus, 142, 550

Woon, D. E. 2001, Icarus, 149, 277

Woon, D. E. 2002, ApJ, 571, L177

Zheng, X., \& Cooks, R. G. 2002, J. Phys. Chem. A, 106, 9939 


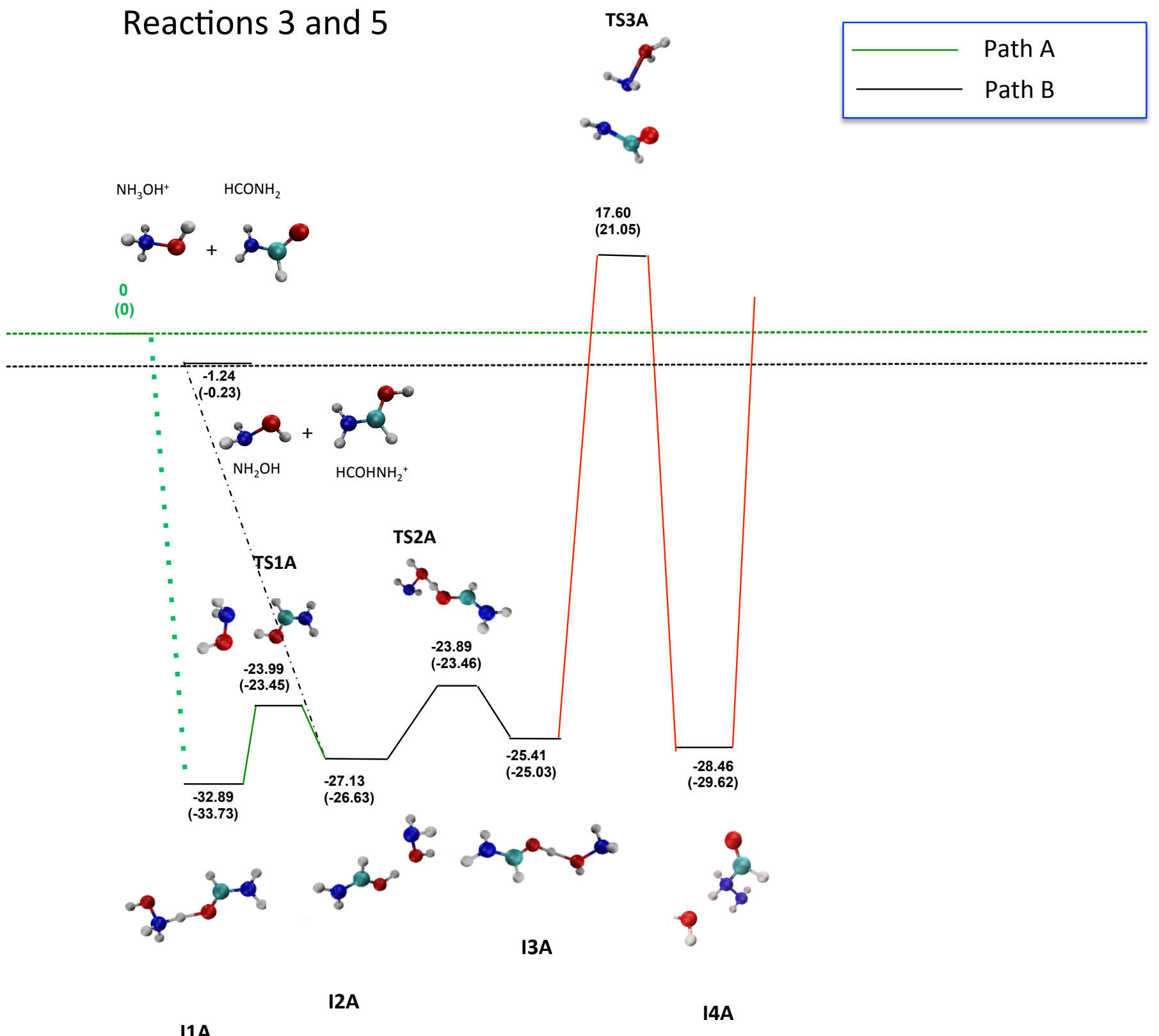

Fig. A.1. Energy profiles, in $\mathrm{kcal} / \mathrm{mol}$, for ion-molecule reactions $\mathrm{NH}_{3}^{+} \mathrm{OH}+\mathrm{HCONH}_{2}(\mathrm{Path} \mathrm{A})$ and $\mathrm{NH}_{2} \mathrm{OH}+\mathrm{HCOHNH}_{2}^{+}\left(\mathrm{Path}_{\mathrm{B}}\right)$, as obtained by CCSD(T)/aug-cc-pVTZ//MP2-aug-cc-pVTZ and MP2/aug-cc-pVTZ (in parenthesis) calculations. These values contain zero-point energies (ZPE). The diagram stops at I4A structure since afterwards it would be the same as Fig. 2.

\section{Appendix A: Complementary reaction diagrams}

Here we report the energy profiles of the reaction pathways, which show activation energy barriers that are too high. Details on the neutral-neutral reaction pathways are given in the following.

\section{A.1. Ion-molecule reactions}

Here we detail the PES for ion-molecule reactions with energy barriers that are too high, so that these reactions are not doable under low temperature conditions. First we discuss reactions 3 and 5, reported in Fig. A.1 as Path A and B, respectively.

The electrostatic interaction between $\mathrm{NH}_{3} \mathrm{OH}^{+}$and the neutral formamide (reaction 3) leads to the formation of the complex I1A. Then, the complex I1A evolves to I2A through a hydrogen migration from the nitrogen to the oxygen atom, involving TS1A. The transition state TS2A connects the two intermediates I2A and I3A, implying the rotation around the torsional angle O-H-O-N. The structures of I1 A and I2A are also reported in Fig. 3. From I3A, the formation of the more stable isomer of protonated urea takes place as described previously. In this case, however, since the reactants are lower in energy, the pathway has a barrier of $17.6 \mathrm{kcal} / \mathrm{mol}$, making this process not possible under low temperature conditions.

The ion-molecule interaction between neutral hydroxylamine with protonated formamide forms the complex I2A (Path B of Fig. A.1). From I2A, the reaction mechanism for the synthesis of protonated urea is the one already described, with a net activation barrier of $18.8 \mathrm{kcal} / \mathrm{mol}$. 


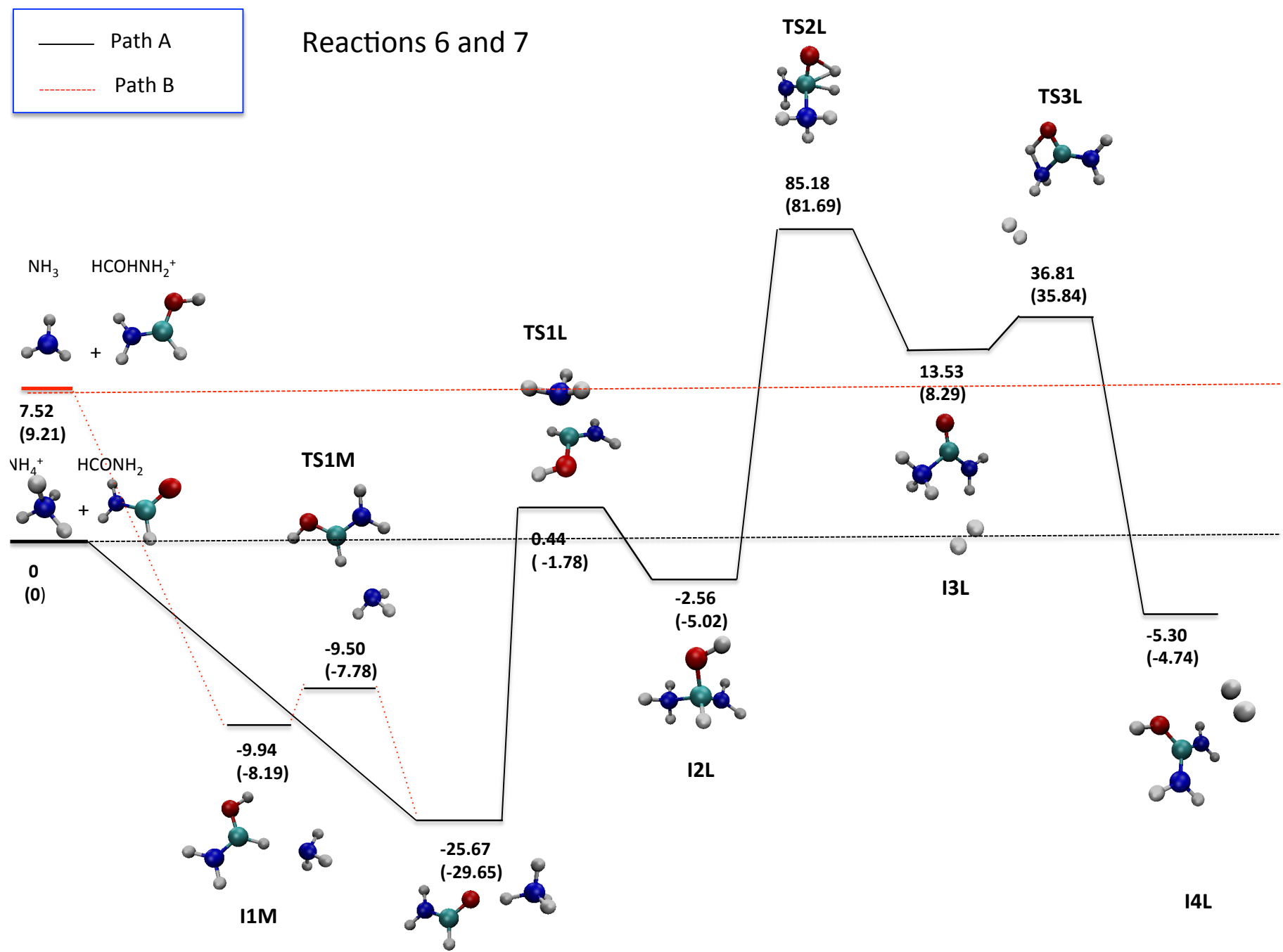

Fig. A.2. Energy profiles, in kcal/mol, for ion-molecule reactions $\mathrm{NH}_{4}^{+}+\mathrm{HCONH}_{2}$ (Path A) and $\mathrm{NH}_{3}+\mathrm{HCOHNH}_{2}^{+}(\mathrm{Path} \mathrm{B})$, as obtained by CCSD(T)/aug-cc-pVTZ//MP2-aug-cc-pVTZ and MP2/aug-cc-pVTZ (in parenthesis) calculations. These values contain zero-point energies (ZPE). In the final step we report the energy of the cluster, the final product energy being reported in Table 1.

We now consider reactions 6 and 7, involving formamide and ammonia (neutral and protonated), whose PES leading to the formation of protonated urea and $\mathrm{H}_{2}$, is shown in Fig. A.2. As we can notice from Path A (corresponding to $\mathrm{NH}_{4}^{+}+\mathrm{HCONH}_{2}$ reactants), the electrostatic interaction between formamide and ammonium ion results in the formation of the complex I1L, where a hydrogen bond interaction between the carbonyl oxygen of formamide and ammonium ion takes place.

The reaction proceeds through TS1L, where the deprotonation of the ammonium ion induces a nucleophilic attack on the carbon atom by the nitrogen atom of ammonia, leading to the formation of I2L. From the tetrahedral intermediate I2L, the reaction evolves to I3L by removing molecular hydrogen through TS2L. This is the rate determinant step of this reaction since it corresponds to the high energy barrier. Then a proton transfer leads to the final products via TS3L transition state. A similar route, in which only the initial steps are different, corresponds to $\mathrm{NH}_{3}+\mathrm{HCOHNH}_{2}^{+}$reaction (Path B in Fig. A.2). In both cases the pathways connecting these reactants to exothermic products have a highly positive barrier, 85.18 and $77.66 \mathrm{kcal} / \mathrm{mol}$ for Path A and B, respectively, and they can be disregarded as possible pathways for the formation of urea in the ISM.

Finally, we discuss the PES of reactions 8 and 9 involving methylamine and formamide, which are reported in Fig. A.3.
The reaction between $\mathrm{CH}_{3} \mathrm{NH}_{2}$ and $\mathrm{HCOHNH}_{2}^{+}$(Path A in Fig. A.3) is somehow particular, showing a feature that can arise when localizing minima and TSs on the Born-Oppenheimer surface and then adding ZPE correction (as always in theoretical chemistry). I1G, the complex between the two reactants, and I2G, an intermediate, are connected via a TS, TS1G. Considering only electronic energy (shown in red in Fig. A.3), the TS is higher in energy than the intermediate $\mathrm{I} 2 \mathrm{G}$, while adding the ZPE on reactants, TSs, and products; now the TS is lower in energy then its corresponding product. We note that the IRC calculation connecting, via the minimum energy path, the TS with the products (in this case $\mathrm{I} 1 \mathrm{G}$ and $\mathrm{I} 2 \mathrm{G}$ ) is done on the BornOppenheimer surface, which does not contain ZPE correction. This means that dynamically, even at $0 \mathrm{~K}$, the $\mathrm{I} 1 \mathrm{G}$ to $\mathrm{I} 2 \mathrm{G}$ isomerization is barrierless. We will not go more in detail on this aspect since we are interested in the highest energy barrier on each pathway, which in the present case does not correspond to this peculiar TS. In fact, from I2G the system needs to pass through TS2G, where the simultaneous cleavage of the $\mathrm{C}-\mathrm{N}$ bond of methylamine and the formation of a new $\mathrm{C}-\mathrm{N}$ bond occur. TS2 $\mathrm{G}$ is the highest energy TS of this reaction pathway with an energy barrier of $70.58 \mathrm{kcal} / \mathrm{mol}$. The other pathway shown in Fig. A.3 (Path B) differs from Path A by the initial steps. First the complex $\mathrm{I} 1 \mathrm{H}$ is formed, then leading to the complex $\mathrm{I} 1 \mathrm{G}$, in which 


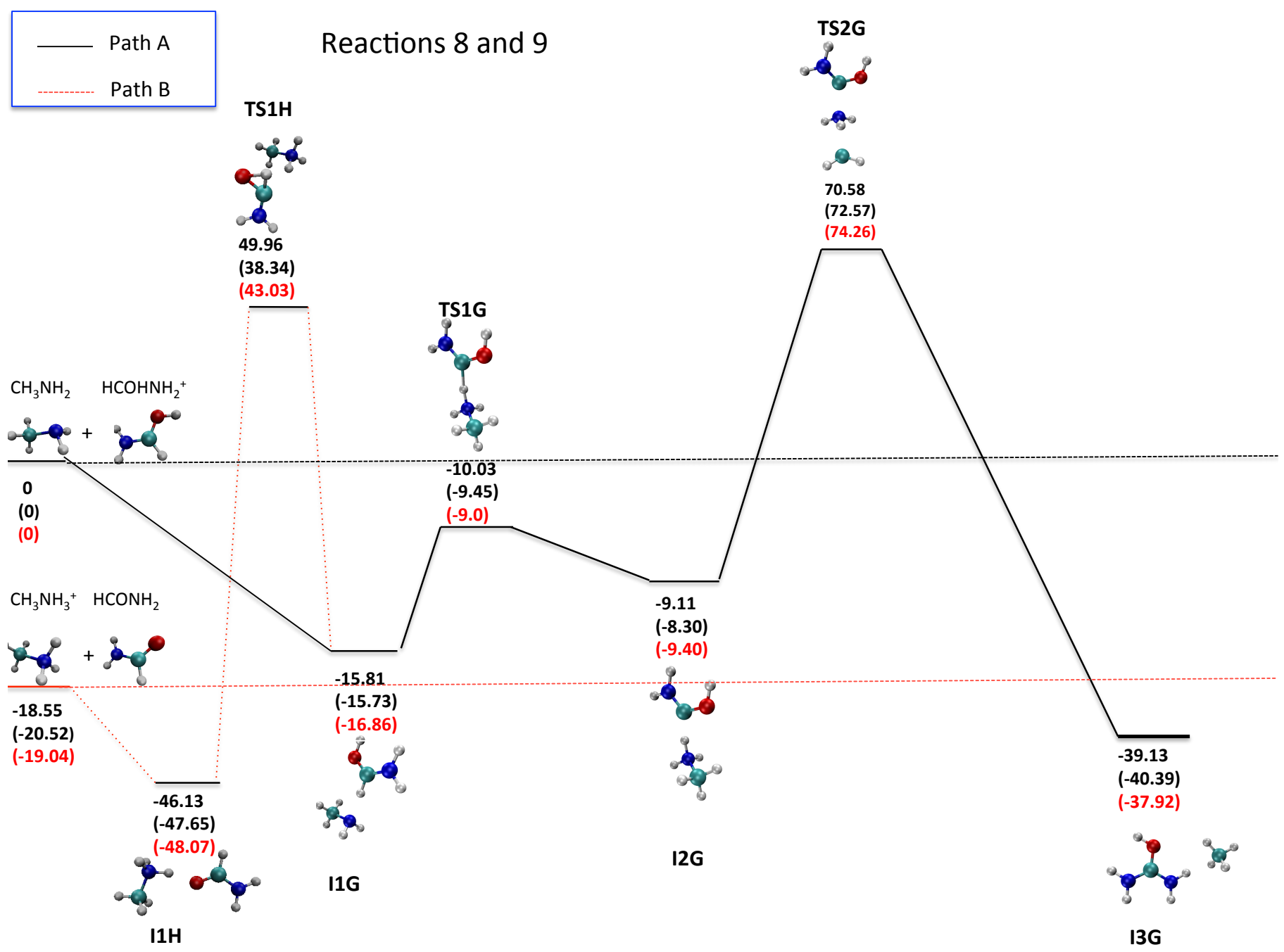

Fig. A.3. Energy profiles, in kcal/mol, for ion-molecule reactions $\mathrm{CH}_{3} \mathrm{NH}_{2}+\mathrm{HCOHNH}_{2}^{+}$and $\mathrm{CH}_{3} \mathrm{NH}_{3}^{+}+\mathrm{HCONH}_{2}$ as obtained by CCSD(T)/augcc-pVTZ//MP2-aug-cc-pVTZ and MP2/aug-cc-pVTZ (in parenthesis) calculations. These values contain zero-point energies (ZPE). In red we report values concerning only electronic energies, which show that $\mathrm{I} 2 \mathrm{G}$ is lower in energy than the TS1G transition state for electronic energies, while ZPE inverts the order (see text for more details). In the final step we report the energy of the cluster, the final product energy being reported in Table 1.

the formamide is now protonated. TS1H is the only structure with a saddle point topology found, since when we try to transfer a proton from the $\mathrm{NH}_{3}$ group of protonated methylammine to the oxygen atom of formaldehyde, the system always come back to structure $\mathrm{I} 1 \mathrm{H}$. However, the rate determining step is the TS2G, which is in common between the two pathways. In fact, once $\mathrm{I} 1 \mathrm{G}$ is obtained then the reaction proceeds as for Path A.

\section{A.2. Neutral-neutral reactions}

In Fig. A.4 we show the PES corresponding to the neutral-neutral reactions. Two pathways were identified, Path A and Path B, and they both show positive barriers such that they cannot be considered as likely to occur under ISM conditions. One pathway, Path A in Fig. A.4, is the neutral-neutral analog of the one between protonated hydroxylamine and neutral formamide. The first step of this process is the formation of the complex I1C, resulting in a hydrogen bond interaction between the amine group of the formamide and the amino group of hydroxylamine. The 1,2-hydrogen shift from the nitrogen atom to the oxygen atom in the hydroxylamine and the successive formation of a new $\mathrm{N}-\mathrm{O}$ bond leads to the intermediate $\mathrm{I} 2 \mathrm{C}$, through the transition state TS1C. This transition state is $61.59 \mathrm{kcal} / \mathrm{mol}$ higher than the reactants and represents the highest energy barrier of this reaction path. The reaction advances through the hydrogen migration from the secondary to the primary amine of $\mathrm{I} 2 \mathrm{C}$ and leads to the formation of the intermediate I3C, involving TS2C. The I3C evolves to the $\mathrm{I} 4 \mathrm{C}$ through the TS4C, where a rotation of the aldehyde group around the $\mathrm{C}-\mathrm{N}$ bond occurs. The I4C progresses through TS5C, where a hydrogen migration from the secondary amino group of I4C to its primary amino group leads to the intermediate I5C. From I5C the reaction reaches I6C through a concerted mechanism, via TS5C: a hydrogen atom migration from the carbon atom to the nitrogen atom of the secondary amino group, which induces the $\mathrm{N}-\mathrm{N}$ bond cleavage and the consequent formation of ammonia. The intermediate I6C is a cluster formed by isocyanic acid, water, and ammonia, similar to what is obtained in the pathway of reaction 4 , here of course all species being neutral. From I6C the reaction progresses to I7C through the TS6C, which implies a proton transfer, assisted by water, from the nitrogen atom of the ammonia molecule to the carbonyl oxygen of the isocyanic acid. This proton transfer favors the nucleophilic attack by the nitrogen atom on the carbonyl 

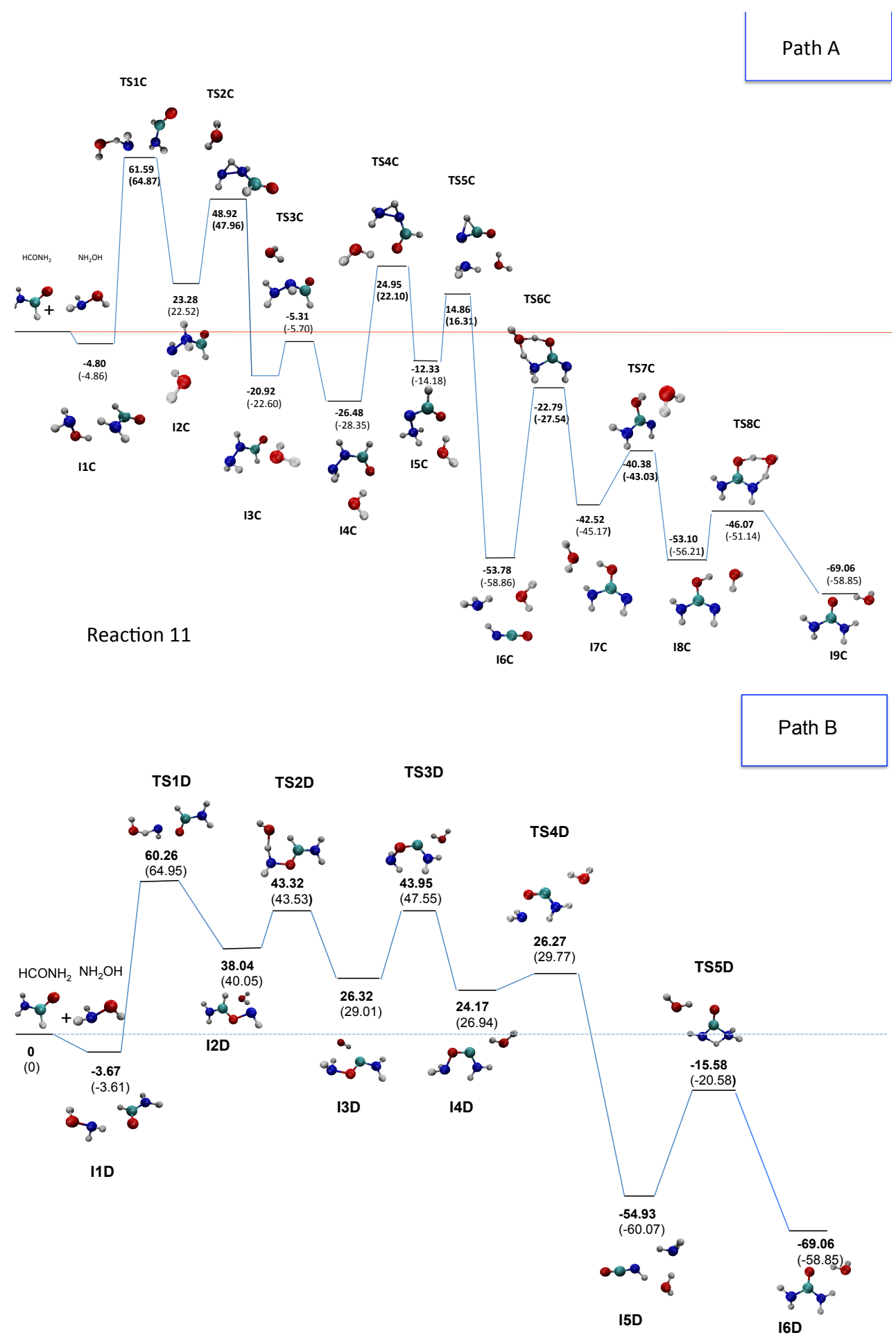

Fig. A.4. Energy profiles, in kcal/mol, for two pathways of neutral-neutral reaction $\mathrm{NH}_{2} \mathrm{OH}+\mathrm{HCONH}_{2}$ as obtained by $\mathrm{CCSD}(\mathrm{T}) / \mathrm{aug}$-ccpVTZ//MP2-aug-cc-pVTZ and MP2/aug-cc-pVTZ (in parenthesis) calculations. These values contain zero-point energies (ZPE). In the final step we report the energy of the cluster, the final product energy being reported in Table 1. Upper panel: Path A; lower panel: Path B.

carbon atom. Then, the rotation of the alcoholic hydrogen around the $\mathrm{C}-\mathrm{O}$ bond takes place in TS7C and leads to I8C. From I8C the urea is produced through TS8C, where a proton transfer, assisted by water, takes place from the oxygen atom to the nitrogen atom.

Path B is shown in Fig. A.4. In this case, the reaction begins with the formation of the complex I1D, which implies a hydrogen bond interaction between the oxygen of formamide and the hydrogen of the amino group of hydroxylamine, and which is slightly less stable than the complex I1C of Path A. The reaction mechanism, which leads from I1D to I2D, then consists in a 1, 2 hydrogen shift from the nitrogen atom to the oxygen atom of the hydroxylamine, with consequent cleavage of the $\mathrm{N}-\mathrm{O}$ bond. The highest barrier for this path is TS1D and it is located $60.26 \mathrm{kcal} / \mathrm{mol}$ above the energy of the reactants. A proton transfer, assisted by water, from the carbon atom to the nitrogen atom leads to the formation of I3D, through TS2D. Then, I3D evolves to I4D via TS3D, where a rotation of the torsional 


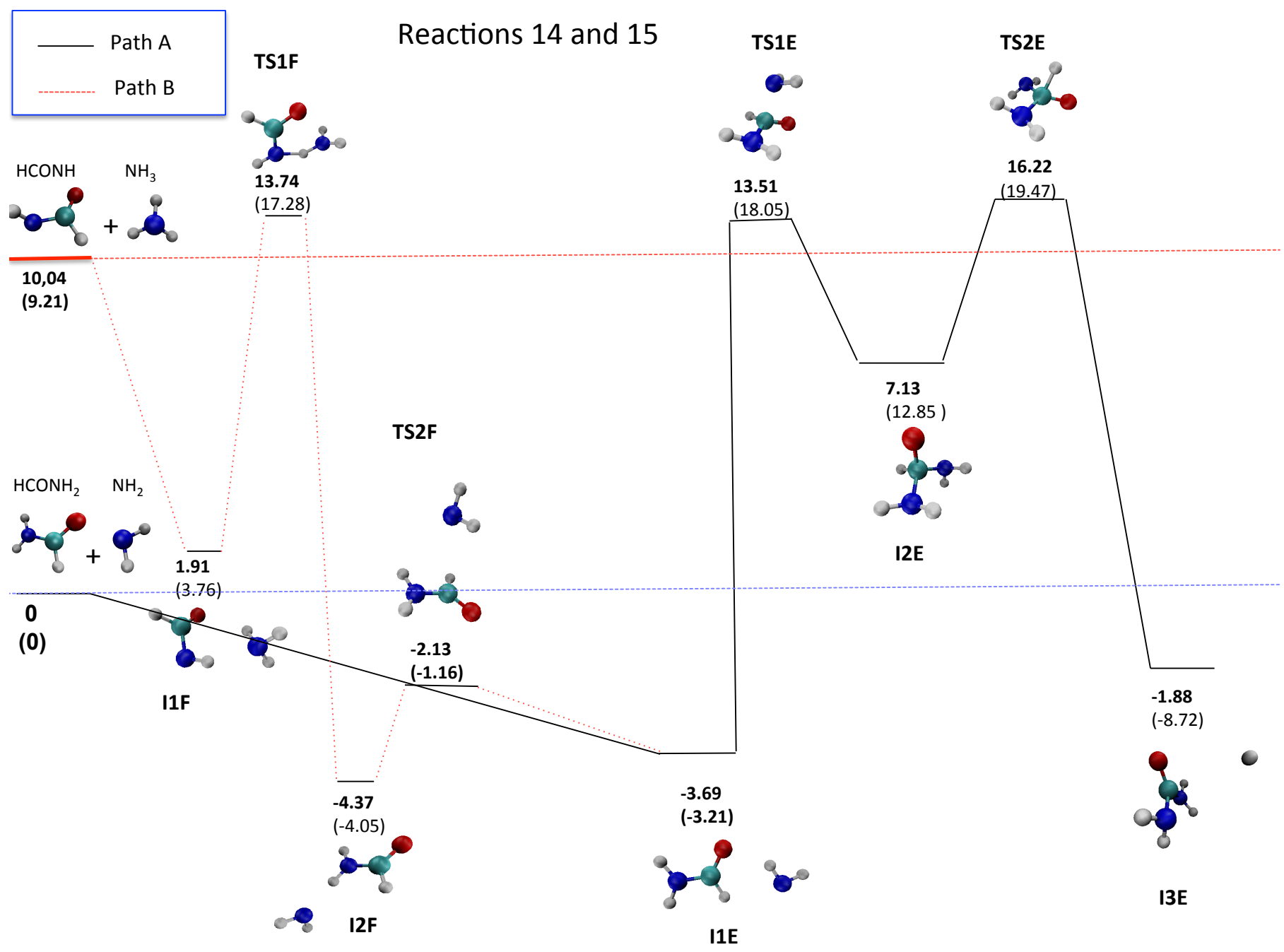

Fig. A.5. Energy profiles, in $\mathrm{kcal} / \mathrm{mol}$, for radical reactions $\mathrm{NH}_{2}+\mathrm{HCONH}_{2}$ (black path) and $\mathrm{HCONH}+\mathrm{NH}_{3}$ (red path) at the $\mathrm{CCSD}(\mathrm{T}) /$ aug-ccpVTZ)//MP2/aug-cc-pVTZ and MP2/aug-cc-pVTZ (in parentheses) levels. Zero-point vibrational energy differences are included.

angle N-O-C-N takes place. The hydrogen abstraction reaction of the amino group by the $\mathrm{NH}_{2}$ group through TS4D leads to the formation of I5D, which is (again) a neutral cluster composed by isocyanic acid, ammonia, and water. From I5D, the hydrogen migration from the nitrogen atom of ammonia to the nitrogen atom of the amino group induces a nitrogen nucleophilic attack on the carbonyl $\mathrm{C}$ atom, leading to I6D, via structure TS5D.

\section{A.3. Radical reactions}

The PESs corresponding to $\mathrm{NH}_{2} \cdot+\mathrm{HCONH}_{2}$ and $\mathrm{NH}_{3}+$ HCONH. are shown in Fig. A.5 as Path A and B, respectively. In both cases the activation energy is positive. In the case of Path A, the reaction starts with the formation of the complex I1E, in which the amino radical interacts with the carbonyl group of neutral formamide. The complex I1E progresses to the tetrahedral intermediate I2E through the TS1E structure, which implies the nucleophilic attack of the nitrogen atom on the carbonyl $\mathrm{C}$ atom. The I2E evolves to the urea through the TS2E, where the homolytic cleavage of the $\mathrm{C}-\mathrm{H}$ bond occurs. Even if this radical reaction is exothermic $(-1.84 \mathrm{kcal} / \mathrm{mol})$, the net activation barrier is $16.22 \mathrm{kcal} / \mathrm{mol}$, making this process unlikely for ISM conditions. The PES profile for Path B, corresponding to the most exothermic and exergonic reaction, is also reported in Fig. A.5. At the beginning the electrostatic interaction between the ammonia and the radical, formamide is responsible for the formation of the complex I1F. Then, the hydrogen abstraction reaction of the ammonia by the nitrogen atom of radical formamide leads from $\mathrm{I} 1 \mathrm{~F}$ to I2F, through TS1F. The I2F evolves to I1E through the reorientation of the amino radical around the formamide molecule. From I1E the system progresses to the products with the same reaction mechanism described previously for Path A. In this case, the activation barrier of the process is smaller than for Path A but still positive $(6.18 \mathrm{kcal} / \mathrm{mol})$, thus making it unlikely for the ISM. 


\section{Appendix B: Proton affinity}

Here we report the proton affinities of molecules observed or for which tentative observations are reported in the Sgr B2 cloud from data listed in the National Institute of Standards and Technology (NIST) web-book. For urea we report also the values obtained from our calculations at 15 and $298 \mathrm{~K}$, and for hydroxylamine (not present in the experimental data-base) we report calculated values at the same temperatures.

Table B.1. Experimental values of available proton affinities (PA) of neutral molecules suggested to be present in the Sgr B2 cloud.

\begin{tabular}{|c|c|c|c|}
\hline Molecule & $\mathrm{PA}(\mathrm{kJ} / \mathrm{mol})$ & Source & Reference \\
\hline \multirow[t]{3}{*}{ Urea } & $868.4 \pm 2.5$ & NIST & Zheng \& Cooks (2002) \\
\hline & 868.432 & calculations at $T=15 \mathrm{~K}$ & This work \\
\hline & 862.549 & calculations at $T=298 \mathrm{~K}$ & This work \\
\hline Cyclopropenylidene & 951.1 & NIST & Hunter \& Lias (1998) \\
\hline Iron oxide & 907 & NIST & Hunter \& Lias (1998) \\
\hline Methylamine & 899.0 & NIST & Hunter \& Lias (1998) \\
\hline Ethanimine & 885.1 & NIST & Hunter \& Lias (1998) \\
\hline $\mathrm{C}_{2} \mathrm{~S}$ & 869.6 & NIST & Hunter \& Lias (1998) \\
\hline Acetamide & 863.6 & NIST & Hunter \& Lias (1998) \\
\hline $\mathrm{N}$-methylformamide & 851.3 & NIST & Hunter \& Lias (1998) \\
\hline Methyl isocyanide & 839.1 & NIST & Hunter \& Lias (1998) \\
\hline Ketene & 825.3 & NIST & Hunter \& Lias (1998) \\
\hline Aminoacetonitrile & 824.9 & NIST & Hunter \& Lias (1998) \\
\hline Formamide & 822.2 & NIST & Hunter \& Lias (1998) \\
\hline Methyl acetate & 821.6 & NIST & Hunter \& Lias (1998) \\
\hline Phenol & 817.3 & NIST & Hunter \& Lias (1998) \\
\hline Ethylene glycol & 815.9 & NIST & Hunter \& Lias (1998) \\
\hline Acetone & 812 & NIST & Hunter \& Lias (1998) \\
\hline Cyanamide & 805.6 & NIST & Hunter \& Lias (1998) \\
\hline Isopropyl cyanide & 803.6 & NIST & Hunter \& Lias (1998) \\
\hline Propylene oxide & 803.3 & NIST & Hunter \& Lias (1998) \\
\hline Ethyl formate & 799.4 & NIST & Hunter \& Lias (1998) \\
\hline Propyl cyanide & 798.4 & NIST & Hunter \& Lias (1998) \\
\hline Propenal & 797 & NIST & Hunter \& Lias (1998) \\
\hline Ethylcyanide & 794.1 & NIST & Hunter \& Lias (1998) \\
\hline Phosphorus mononitride & 789.4 & NIST & Hunter \& Lias (1998) \\
\hline Propanal & 786 & NIST & Hunter \& Lias (1998) \\
\hline Vinylcyanide & 784.7 & NIST & Hunter \& Lias (1998) \\
\hline Acetic acid & 783.7 & NIST & Hunter \& Lias (1998) \\
\hline Methyl formate & 782.5 & NIST & Hunter \& Lias (1998) \\
\hline Methyl cyanide & 779.2 & NIST & Hunter \& Lias (1998) \\
\hline Silicon monoxide & 777.8 & NIST & Hunter \& Lias (1998) \\
\hline Ethanol & 776.4 & NIST & Hunter \& Lias (1998) \\
\hline Methyl mercaptan & 773.4 & NIST & Hunter \& Lias (1998) \\
\hline Amino radical & 773.4 & NIST & Hunter \& Lias (1998) \\
\hline Hydrogen isocyanide & 772.3 & NIST & Hunter \& Lias (1998) \\
\hline Methyl isocyanate & 764.4 & NIST & Hunter \& Lias (1998) \\
\hline Acetaldehyde & 768.5 & NIST & Hunter \& Lias (1998) \\
\hline Thioformaldehyde & 759.7 & NIST & Hunter \& Lias (1998) \\
\hline Methanol & 754.3 & NIST & Hunter \& Lias (1998) \\
\hline Isocyanic acid & 753 & NIST & Hunter \& Lias (1998) \\
\hline Cyanoacetylene & 751.2 & NIST & Hunter \& Lias (1998) \\
\hline Methyl-acetylene & 748 & NIST & Hunter \& Lias (1998) \\
\hline Formic acid & 742.0 & NIST & Hunter \& Lias (1998) \\
\hline Water & 691 & NIST & Hunter \& Lias (1998) \\
\hline Carbonyl sulfide & 628.5 & NIST & Hunter \& Lias (1998) \\
\hline $\mathrm{N}_{2} \mathrm{O}$ & 575.2 & NIST & Hunter \& Lias (1998) \\
\hline Nitric oxyde & 531.8 & NIST & Hunter \& Lias (1998) \\
\hline Hydrogen fluoride & 484 & NIST & Hunter \& Lias (1998) \\
\hline
\end{tabular}

